\title{
Book review: Intercultural communication with Arabs: studies in educational, professional and societal contexts
}

(Raddawi, R., 2015, Springer)

\author{
Ginger Silvera \\ Zayed University, UAE
}

Raddawi's latest edited book Intercultural Communication with Arabs offers insight on the Arab student population, providing depth on educational, professional and societal contexts. Intercultural communication in the Middle East is a relatively new area of research compared with the number of studies focusing on the Western world and East Asia. Recently, there have been a few books published that focus on an international perspective of Intercultural Communication (IC) (Samovar et al., 2014; Asante et al., 2013). However this is one of the first books that explores the Arab World setting. As the Middle East continues to be a thriving economy, this book brings attention to connecting with people with different backgrounds, especially the culture of Arab societies. In chapter one, Raddawi notes

In its simplest form, IC means the sharing or exchange of messages between people of different cultural and/or social backgrounds. (p.1)

This book provides the perspective from authors that share the Arab culture or have experience living in the region.

This review focuses on the key issues discussed in the book's 19 chapters related to how to communicate with the Arab student population. The section on educational context has eight chapters, and the professional and societal themes have five chapters each. In the second chapter Irene Theodoropoulou explores the communication style between instructor and students. For example, in email communication the contributor suggests Arab students overemphasize emotions in comparison to students in the western world. The chapter builds off Hofstede's (1980) cultural values theory, which suggests Arabs communicate in a high context culture based on interpersonal communication.

In chapter 3 Sanhya R. Mehta and Ayesha Heble focus on stereotypes amongst the Indian community within Oman. The contributors argue that intercultural communication has mostly focused on the western world but in the Middle East a large population are expatriates. For example, a large expatriate community are Indians and are composed of both middle and lower classes in Oman. Omani citizens rarely interact with Indians and have often developed perceptions that they are lower class citizens. This chapter sheds light on the discrimination that exists and how to help integrate cultures such as offering interdisciplinary courses at the university.

The next two chapters focus on Saudi Arabia; in chapter 4 Magdalena Karolak and Hala A. Guta discuss the development of tertiary education to adapt to a knowledge base economy. Building off Hofstede's five dimensional model (2001) they explore the relationships between faculty and students since the majority of faculty are foreigners. One of the interesting findings was on communication. Arab students feel more comfortable speaking Arabic to their Arab professors, but also recognize they need to speak English with westerners in order to develop their careers. They recommend for foreign professors to be culturally sensitive to students' communication skills; and for Arab professors to lessen the likelihood 
they resort to using Arabic to explain concepts to students, in order to help students develop their English.

In chapter 5 Manssour Habbash and Salah Troudi stress the importance of Saudis learning the English language. This issue has been surrounded by a debate that Saudis can lose their culture and language by being overexposed to the use of the English language. In order for Saudis to compete in the modern world, the command of the English language is important. Arabic is deemed as a local language that can be used to teach subjects such as religion. The contributors suggest developing better attitudes toward the English language.

In chapter 6 Georgia Daleure et al. discusses family involvement for Emirati students in higher education. The Emirates is a new country, and the influx of expatriates teaching locals is high. Therefore, there is need to understand the culture to help improve methods in teaching and communication. The contributors address the various social factors that influence Emiratis to pursue higher education and whether parenting styles differ amongst genders. They find that families are generally supportive of students pursuing higher education, for example by providing emotional and financial support. As the the Emirati people gains higher education levels the support for future generations to succeed is relatively high.

In chapter 7 Melanie Gobert sheds light on the issue of taboo topics that are considered to be Haram (Arabic for forbidden) in Middle Eastern classrooms. Sensitive topics include abortion, sex, politics, fortune telling, and ghosts. For example, discussing hugging, kissing and dancing between a male and female in public is considered taboo. However, if it is public and between the same genders it is acceptable. The contributors suggest there are certain topics that can be used as learning tools. Instructors need to discuss with their colleagues or supervisors to determine which topics may be suitable for students. This would help prevent any misunderstandings.

In chapter 8 Khawlah Ahmed discusses the need for teachers to be culturally sensitive to Muslim students especially in the American context. In the Western world, there are have been numerous issues that marginalize Muslims. American Muslims undergo challenging scrutiny whether by their peers or through media based on stereotypical information. Therefore, the contributor points out the need for intercultural training emphasizing the role of teachers and administrators to be culturally competent.

In chapter 9 William DeGenaro sheds light on the importance of night school and teaching English as a second language in Beirut, Lebanon to university students and university hospital staff. Instructors are undergraduate student volunteers interested in advocating civic engagement. The author finds volunteers were more apt to offer their services, because they were interested in social change. Night school students receive a comprehensive education, which also includes efforts to promote secularism and Arab Nationalism.

The professional context of the book begins in chapter 10. Linzi J. Kemp focuses on the culturally different perspectives of time for meetings. The contributor uses the framework of monochronicity and polychronicity on understanding intercultural meetings. The contributor finds that meetings tend to be polychronic and begin when all participants are present regardless of the slated time. Meeting time is treated different in the Arab culture than in Western culture.

In chapter 11 Rana Raddawi discusses intercultural communication in medical settings and how medical doctors from different cultural backgrounds address the needs of Arabic speakers. The contributor points out that interpreters for medical providers could include errors in their translation when communicating patients' needs; this can also affect patients' medical treatments. Therefore, Arab 
speakers prefer to attend medical appointments with family members who can translate for them. The contributor finds there is a need for skilled medical interpreters in the United Arab Emirates. The dominance of the English language has lessened the likelihood that the Arabic language is used in medical facilities. In addition, physicians need to be trained on cultural competency on how they question their patients' personal activities, since for some cultures sharing personal information is quite sensitive.

In chapter 12 Omar Fayez Atari explores the use of the political television interview for examining the interactions between a Western interviewer, Arab interviewees and how this can affect the perception for the audience. The contributor uses the framework of high and low context communication to analyze the interview. The interviewer uses topic chaining in order to challenge the interviewees' claims on opposing Yasser Arafat in Palestine. Overall, the interviewer relied on a low context communication whereas the interviewee responded in a high context system, which results in a competitive style interview.

The next two chapters examine the use of social networks and how they aid individuals in voicing their political grievances. In chapter 13 Asiya Daud emphasizes the use of social media technology and the rising youth population in the Middle East, which led to democratization in the MENA region. The contributor finds that cyber dissent such as Facebook aids youth to further their freedom of speech. As press outlets censor media in this region, youth are more likely to resort to social media to voice their concerns. The contributor finds that the higher levels of censorship are associated with lower levels of cyber dissent. This could be due to fear of political repercussions. International organizations could advocate for constructive freedom of speech and assist the youth population.

There are numerous dialects of Arabic and in chapter 14 Radia Kesseiri suggests the use of Modern Standard Arabic (MSA) to appeal to the masses during the the 'Arab Spring' revolutions. The contributor points out that leaders in the MENA region are increasingly relying on the use of MSA, which resonates with the educated community. She explores the use of political speeches using MSA, with examples from Egypt's Mubarak, Ben Ali of Tunisia, Gaddafi of Libya and Assad of Syria. The political speeches advanced the use of the Arabic language using MSA, especially in written communication.

The societal context of the book begins in chapter 15. Hayfaa A. Tlaiss discusses that Arab women in Lebanon have increasing freedom when it comes to voting and education. The contributor finds that Lebanese women also receive more family support to get married and have kids, then pursuing an education. Today many women are pursuing degrees and working in positions that are geared toward women. The contributor finds that these cultural values hinder women's' ability to be promoted to higher levels in management. Parents play a key factor in the career decisions of their daughters; therefore, businesses in the Arab world need to consider the cultural context of Arab societies when hiring women.

In chapter 16 Michael J. Oghia explores the concept of love and dating in Lebanon among students at the American University of Lebanon. The family influences marriage partners in a collective culture, whereas romantic love is emphasized in an individualistic culture. Families in the Arab world influence marriage partners to ensure proper family ties and reinforce the ability for the family to have access to financial capital and resources. The contributor finds that Arab students question the concept of love from western influences but are interested in pursuing romantic love.

In chapter 17 Geoff Harkness provides an interesting approach by observing the role of female athletes' intercultural communication between ethnic groups such as Kurds and Arabs. The tensions between two 
groups have mostly been due to political reasons. The contributor finds that these two groups segregate themselves on campus and engage in ethnic slurs. However, when they engage in sports the dynamic changes since the two groups are getting to know each other more and adapt to the team sportsmanship identity.

Music is explored in social context in chapter 18. Zenzele Isoke studies Arab black female hip-hop artists and how their music sheds light on political issues impacting social identities. It provides an interesting approach to understanding black women and feminism in Dubai. Through ethnographic research it touches on racism for blacks, Arab culture and how hip-hop is used as a social expression. This study provides support that hip-hop can be used as a positive tool, especially for Arab Black Muslims.

Lastly, in chapter 19 Sara Abdul-Hadi et al. argues that the UAE has created many programs to accommodate the disabled population, but can create additional efforts to encourage its citizens to accept individuals living with disabilities. The contributor explores societal perceptions toward disabled individuals by determining perceptions are mostly discriminatory toward disabled individuals. Therefore, cultural attitudes need to change and the contributors suggest a few approaches such as raising awareness through media and education.

This book provides a valuable comprehensive overview, by discussing various themes to assist anyone interested in learning more about intercultural communication with Arabs. This book provides various perspectives on communication involving Arabs such as what topics to include in course materials, and how to develop working relationships with students. In addition to communication, the contributors provide basic information about the culture. This can help foreigners adapt to when working in the Arab World. Overall, the chapters fit together well with each other and can assist anyone in teaching within the Middle East, as well as anyone interested in doing business in this part of the world.

\section{References}

Asante, M. K., Miike, Y., \& Yin, J. (2013). The global intercultural communication reader. Routledge.

Hofstede, G. (1980). Culture's consequences: International differences in work-relate values. Beverly Hills: Sage.

Hofstede, G. (2001). Culture's consequences: Comparing values, behaviors, institutions, and organizations across nations ( $2^{\text {nd }}$ ed.). Thousand Oaks: Sage Publications.

Samovar, L. A., Porter, R. E., McDaniel, E. R., \& Roy, C. S. (2014). Intercultural communication: a reader. Cengage Learning. 